\title{
Free dentistry for fishermen continues success
}

\author{
After winning The 2019 Dental Awards' 'Best \\ Outreach or Charity Initiative', this year's \\ \#SmilesAtSea tour of Cornwall and Devon was \\ once again a resounding success. In total 173 \\ members of the fishing community received \\ free dental checks and emergency treatment \\ from Smile Together, making it the most \\ successful tour yet. \\ \#SmilesatSea visited nine fishing ports in \\ three weeks - from Newlyn and Hayle in the far \\ West to Brixham in the South and Ilfracombe \\ in the North. The dental team were joined by \\ a number of other local healthcare providers \\ from physiotherapists to healthy lifestyle \\ advisors, cancer specialists and podiatrists, all \\ providing free treatment. \\ This is the third year that fishermen and their \\ families in the South West have been offered \\ free dental checks and treatment. \\ The health checks were a particular success \\ with almost half of the dental patients taking \\ the opportunity to have their personal MOT, \\ including blood pressure, weight, cholesterol \\ and blood sugar checks.
}

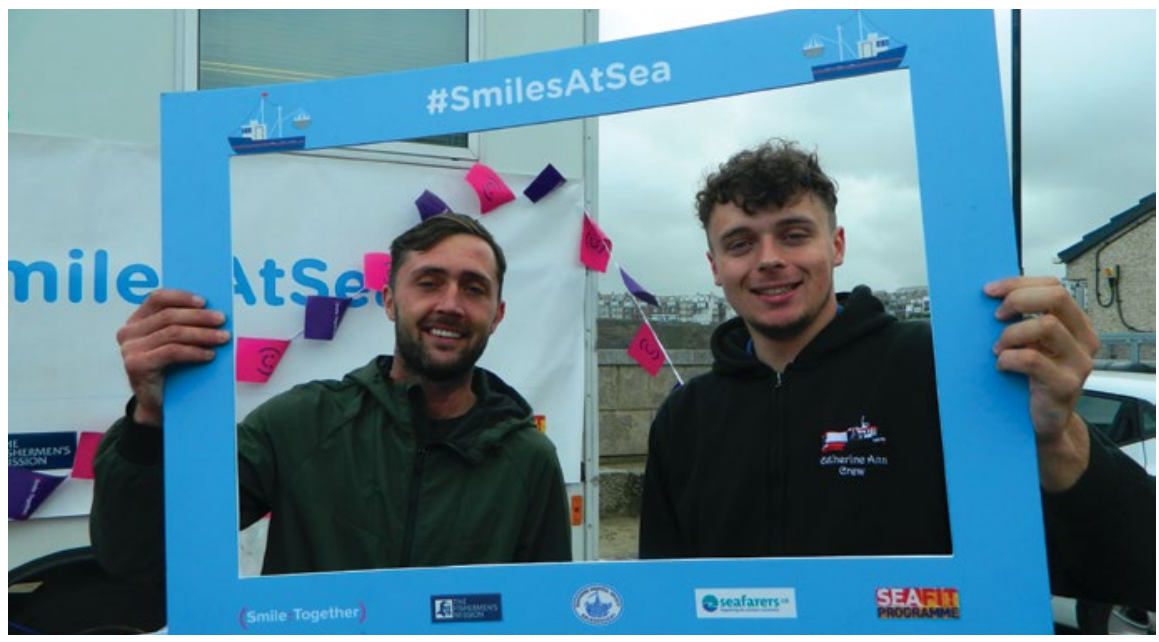

The local Fishermen's Mission have, once again, been crucial to the success of the tour. Speaking about the impact of the tour in Devon, Matt Skinner, the Fishermen's Mission Area Officer in Brixham, said: 'The fishermen really welcome these local health events and it encourages them to seek help. I'm often much busier after events like this with people asking for advice and support, so the more we can do, the better.'

One fisherman commented: 'Can't tell you how great it is that you've been here today. I haven't had my teeth checked in a long time. They are now much cleaner and I feel a lot better, and I now have a referral to mend my broken teeth so I am very happy'.

\section{Author Q\&A: Nikolai Stankiewicz}

The $B D J$, in association with the British Dental Association (BDA), has published Infection control in primary dental care, part of the series of books: the BDJ Clinician's Guides. We spoke to one of the authors of Infection control in primary dental care, Nikolai Stankiewicz, to find out more about it [Martin Fulford is now retired].

\section{Why should people read this book?}

Infection control is a fundamental aspect of the safe delivery of dental care. Maintaining a contemporary knowledge of how this can be achieved is essential.

\section{Who is it aimed at?}

Effective infection control depends upon the whole dental team playing their part. Subsequently we wrote it with the whole team in mind.

\section{Did you enjoy writing it?}

It was certainly a challenge! We both are passionate about this subject, and the writing process really allowed us to delve deep into researching each topic. It was hard not to get side tracked (too often) by the vast amount of information we had to wade through to draw out what would be salient for our readers.

\section{What made you write it?}

We recognised the need to make an accessible guide for the whole dental team. Technical guidance documents don't tend to explain the rationale for why various infection control measures are undertaken. We are of the opinion that if the dental team understands infectious risks and prevention they will be better at what they do.

\section{What are the key issues in this area? The safe delivery of dental care is a primary goal of infection control. The fundamental areas covered by standard precautions remain key issues including. Hand hygiene compliance and effective reprocessing of instruments are areas where we cannot be complacent. An interesting, and challenging contemporary issue, is how this integrates with sustainability in healthcare.}

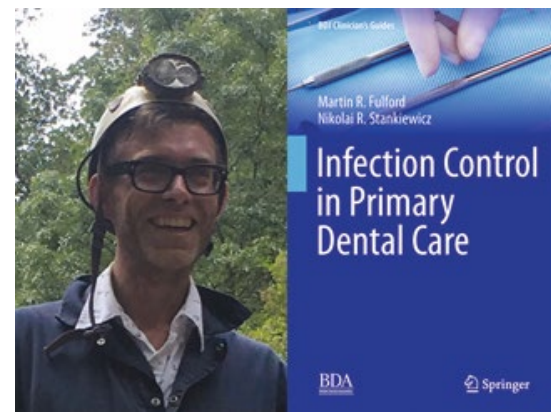

Any advice for future authors of BDJ Clinician's Guides?

Reflect your passion for your subject in your writing.

\section{What do you do in your spare time?} I enjoy exploring the outdoors with my family (and dog) through geocaching and caving.

\section{What other dentistry books would you highly recommend?}

I'd implore my colleagues to own a copy of Antimicrobial prescribing for general dental practitioners published by the Faculty of General Dental Practice.

https://shop.bda.org/icpdc 